\title{
The dynamic simulation of the natural gas transportation
}

\author{
Cristian EPARU* $*^{\mathrm{a}}$, Renata RĂDULESCU ${ }^{\mathrm{a}}$ and Doru STOICA ${ }^{\mathrm{b}}$ \\ ${ }^{a}$ Department of Drilling, Extraction and Transport of Hydrocarbons, \\ ${ }^{b}$ Department of Information Tehnology, Mathemathics and Physics \\ Petroleum - Gas University of Ploiesti
}

\begin{abstract}
The natural gas consumption of the operators connected to the gas transport system depends on the gas needs. As gas needs vary in time, the whole process of gas transportation is, therefore, nonstationary.

The paper presents nonstationary simulations for a gas transportation network and highlights the parameters values (flows, pressures) that are necessary to assure the safety of the system.
\end{abstract}

Keywords: transportation, gas, dynamics, simulation.

\section{Introduction}

Romania was one of the first countries in Europe to exploit its natural gas resources and to develop a transportation system and distribution systems. In the present, the Romanian gas transportation system covers the entire country and it has connections with almost all its neighbouring systems. The network of natural gas transportation is currently administered and operated by SNTGN Transgaz SA.

The dynamics of the gas transportation system is affected by a series of factors that may be: quantifiable, prognosticable or unaccounted for. The natural gas consumption of different clients varies in accordance with their needs. As a result, the process of natural gas transportation is a nonstationary process.

Therefore, when establishing the daily schedule for the day/ days to come and when operating the system, one should consider the dynamics of the process. The results of every manoeuvre being executed in the network are verified by means of dynamic simulations.

This paper presents an analysis of the nonstationary flow process for a network of natural gas transportation. In order to better study the process of gas transportation through pipelines, in the Simone simulator it was reconstructed a gas transportation network with all real-like components: pipelines, valves, regulators, compression stations, gas sources and consumers.

All nonstationary simulations are carried out with Simone, a state-of-the-art numerical simulator used by most of the European and Asian countries for the management of their gas transportation networks.

\section{The description of the network and of the simulation scenarios}

The constructed network consists of 78 pipelines with diameters between 0.15 and $1 \mathrm{~m}$ and a total length of $939.62 \mathrm{~km}, 7$ valves, 4 regulators, 3 compression stations, 7 gas sources - three of which are import sources and 22 consumers -3 industrial ones and 19 towns whose consumption profile is considered to be similar to the one of the domestic consumers.

Figure 1 represents the diagram of the natural gas transportation network.

Daily average values of the flows delivered through output points are estimated by means of the consumption profiles determined on the basis of air temperature, day of the week and areal consumption behaviour. In order to estimate the dynamics of the consumption, there are used hourly profiles defined by means of statistical analysis of the consumption history. 


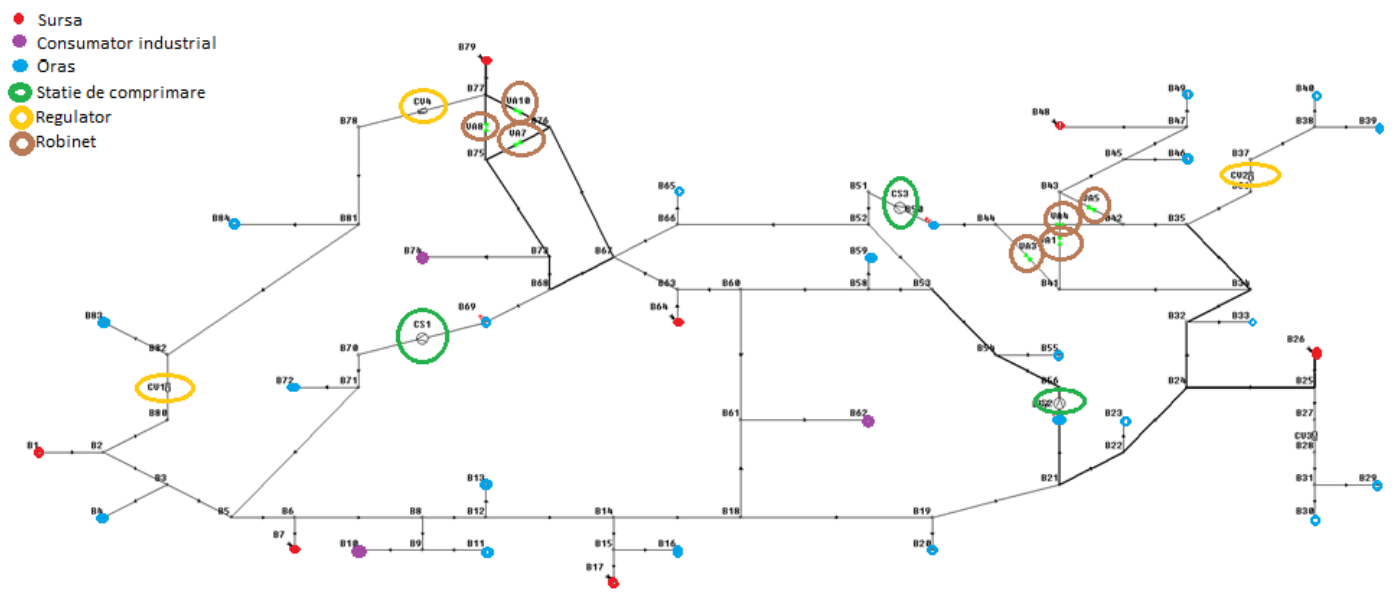

Fig. 1 The diagram of the network

There are two types of consumption profiles: P1 for domestic clients and P2 for industrial consumers. In Table 1, the two consumption profiles are presented on hourly and weekly basis. The variation of the hourly gas consumption is being obtained by multiplying the values in the table below with the medium hourly gas quantity.

Table 1 Consumption profiles

\begin{tabular}{|c|c|c|c|c|}
\hline & \multicolumn{2}{|c|}{ Monday-Friday } & \multicolumn{2}{c|}{ Saturday-Sunday } \\
\hline & $\mathrm{P} 1$ & $\mathrm{P} 2$ & $\mathrm{P} 1$ & $\mathrm{P} 2$ \\
\hline $0: 00$ & 1 & 0 & 1 & 0 \\
\hline $2: 00$ & 1.1 & 0 & 1.1 & 0 \\
\hline $4: 00$ & 1.1 & 0 & 1.1 & 0 \\
\hline $6: 00$ & 1.1 & 0 & 1.1 & 0 \\
\hline $8: 00$ & 1.1 & 1 & 1.1 & 0 \\
\hline $10: 00$ & 1 & 1 & 1 & 0 \\
\hline $12: 00$ & 1 & 1 & 1 & 0 \\
\hline $14: 00$ & 0.9 & 1 & 0.9 & 0 \\
\hline $16: 00$ & 0.9 & 1 & 0.9 & 0 \\
\hline $18: 00$ & 1 & 0 & 1 & 0 \\
\hline $20: 00$ & 1 & 0 & 1 & 0 \\
\hline $22: 00$ & 1 & 0 & 1 & 0 \\
\hline $1100: 00$ & 1 & 0 & 1 & 0 \\
\hline
\end{tabular}

In order to better observe the dynamics of the transportation process, the scenarios cover 10 days
(Fig. 2). There were designed two types of scenarios for summer and winter conditions, respectively.

Table 2 presents the introduction in the scenario of the operating conditions, of the gas quantities that are to be delivered, of the gas injection pressure and of the functioning limits for some of the network's components.

\section{The analysis of results}

During simulations, there were obtained numerous results, from which we selected the most relevant. Figure 3 presents the variation of pressure in a source throughout the 10 days of surveyed consumption.

After having introduced the hourly consumption profiles for the system's outputs, there result the variations of flows for the domestic consumers (namely 19 towns) and the industrial ones, as represented in Figure 4 and Figure 5. In Figure 5, one may notice that the industrial consumption is null during the week-end. In order to demonstrate the dynamic character of the transportation process, in Figure 6 we present the variation of pressure in a pipeline (blue represents the input pressure and grey - the output pressure). One may notice that the two curves are similar, but the amplitude of the output pressure is much higher than the input one. 


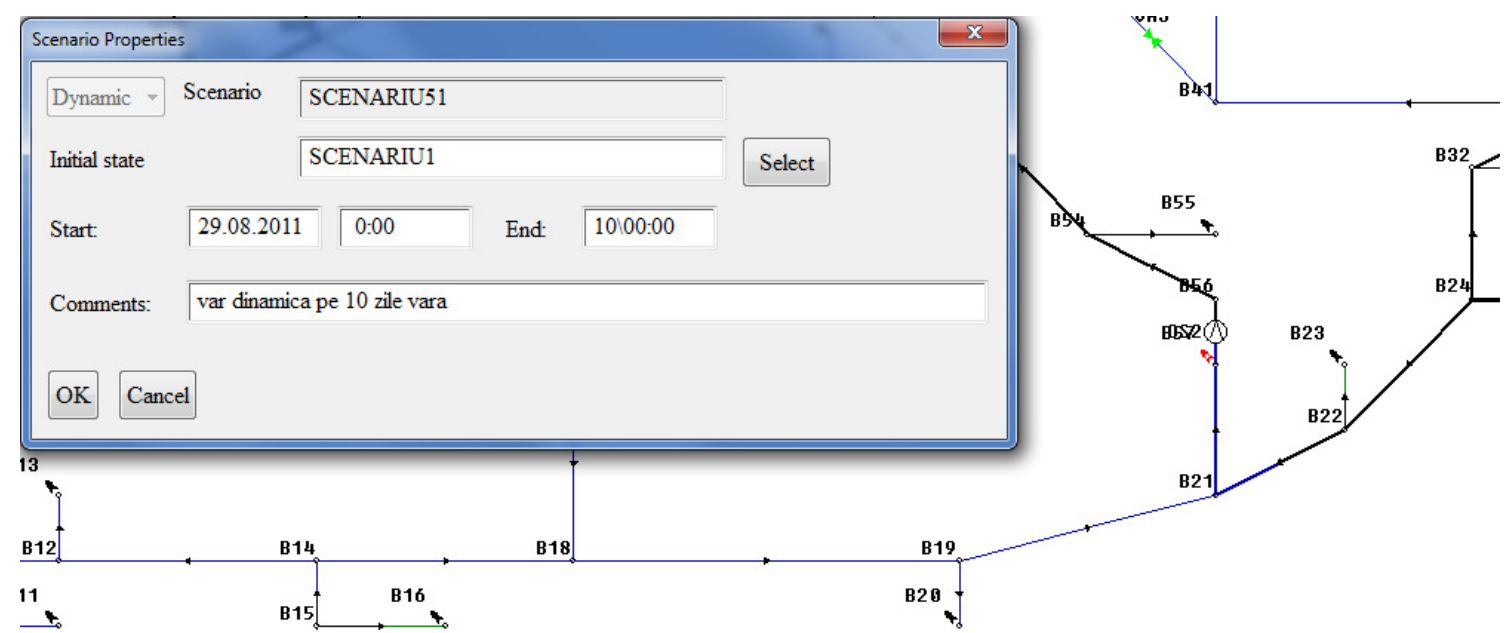

Fig. 2 Defining the 10-day scenario

Table 2 Scenario type

$\begin{array}{ll}\text { Object } & \text { Type } \\ \text { B84 } & \text { NO Node } \\ \text { B83 } & \text { NO Node } \\ \text { B10 } & \text { NO Node } \\ \text { VA7 } & \text { VA Valve } \\ \text { CV4 } & \text { CV Control valve } \\ \text { CS1 } & \text { CS Compressor station } \\ \text { B84 } & \text { NO Node } \\ \text { B79 } & \text { NS Supply node } \\ \text { B74 } & \text { NO Node } \\ \text { B49 } & \text { NO Node } \\ \text { B48 } & \text { NS Supply node } \\ \text { B26 } & \text { NS Supply node } \\ \text { B10 } & \text { NO Node } \\ \text { B1 } & \text { NS Supply node }\end{array}$

Parameter

$\begin{array}{ll}\text { Value } & \text { Unit } \\ \text { P1VARA*40000. } & \mathrm{Nm}^{3 / h} \\ \text { P1VARA*40000. } & \mathrm{Nm}^{3} / \mathrm{h} \\ \text { P1VARA*20000. } & \mathrm{Nm}^{3} / \mathrm{h}\end{array}$

Q Supply/Offtake

Q Supply/Offtake

Q Supply/Offtake

OFF Close

SPO Output pressure setpoint $\quad 20 \quad$ Bar

SPO Output pressure setpoint $\quad 40 \quad$ Bar

L.P Lower limit of Pressure $\quad 4.8 \quad$ Bar

PSET Set pressure $\quad 40 \quad$ bar

L.P Lower limit of Pressure $\quad 4.8 \quad$ bar

L.P Lower limit of Pressure $\quad 5 \quad$ bar

PSET Set pressure $28 \quad$ bar

PSET Set pressure $\quad 40 \quad$ bar

L.P Lower limit of Pressure $\quad 3.6 \quad$ bar

PSET Set pressure $\quad 40 \quad$ bar




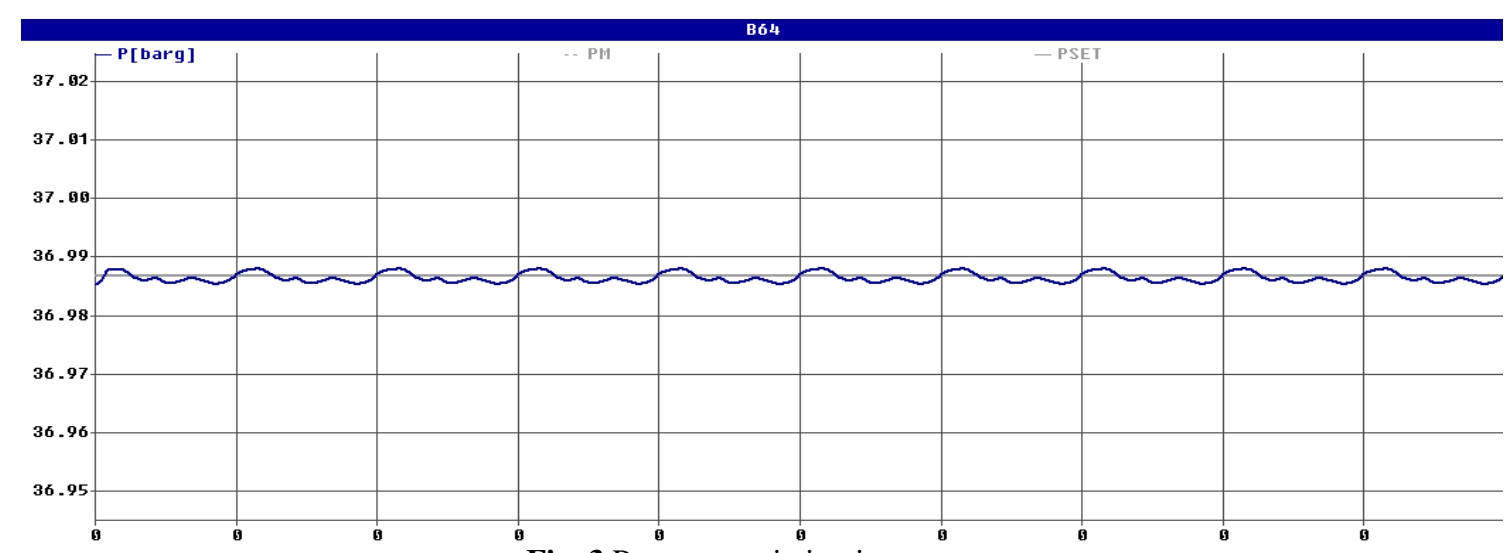

Fig. 3 Pressure variation in a source

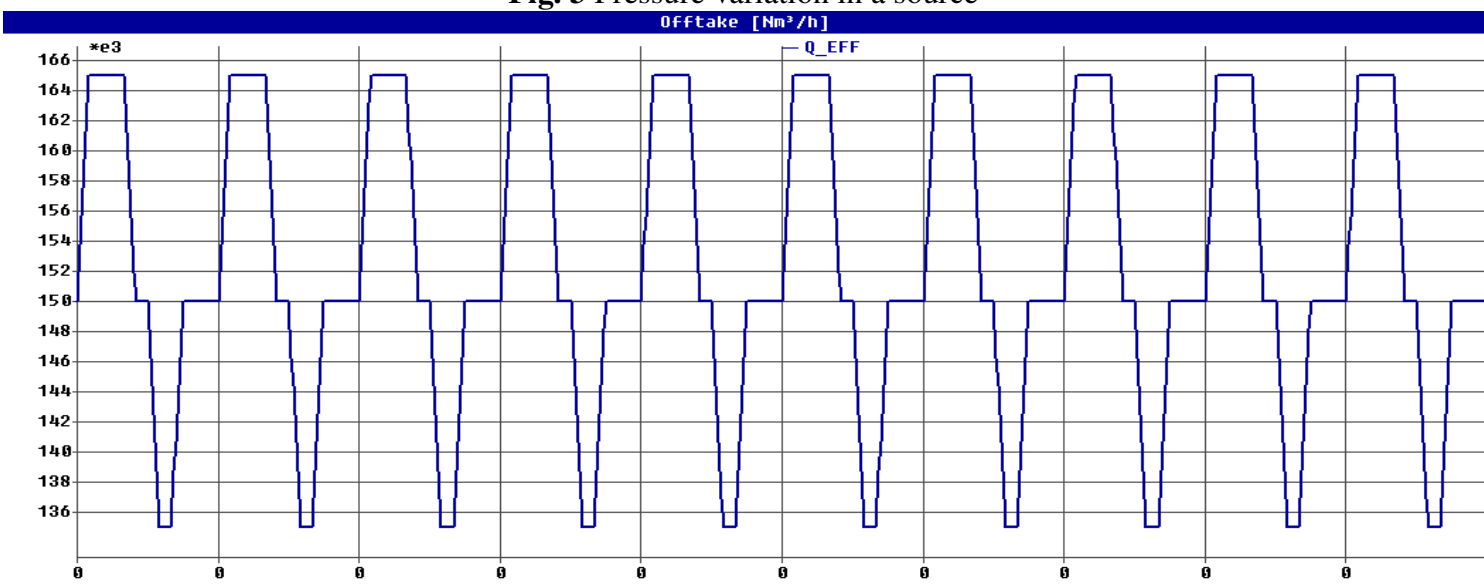

Fig. 4 Flow variation for a domestic consumer

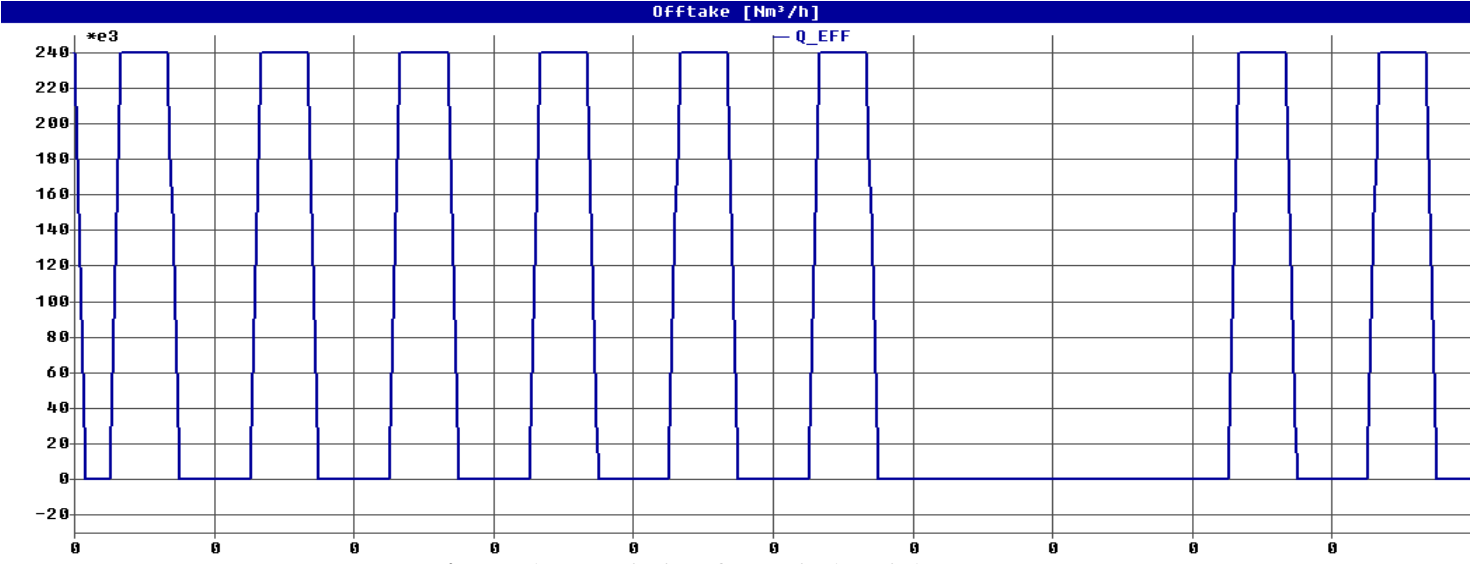

Fig. 5 Flow variation for an industrial consumer 


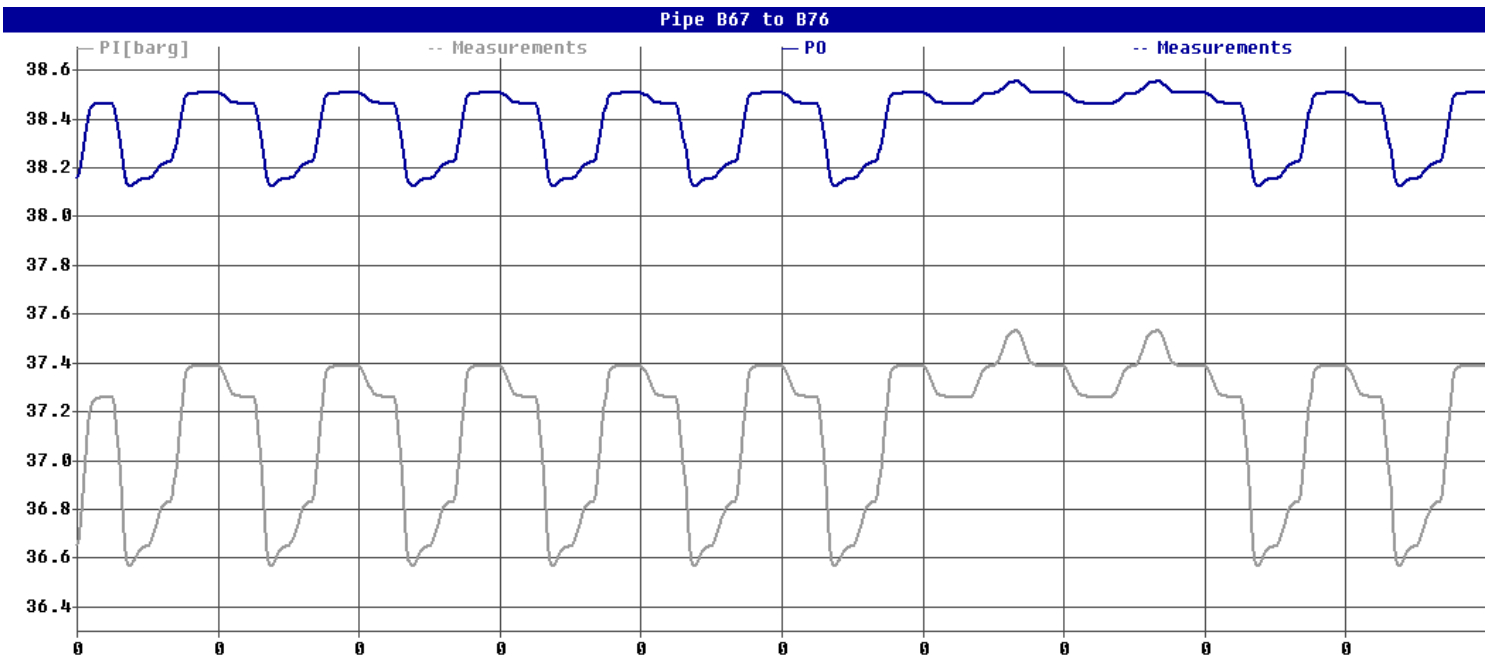

Fig. 6 Pressure variation in a pipeline

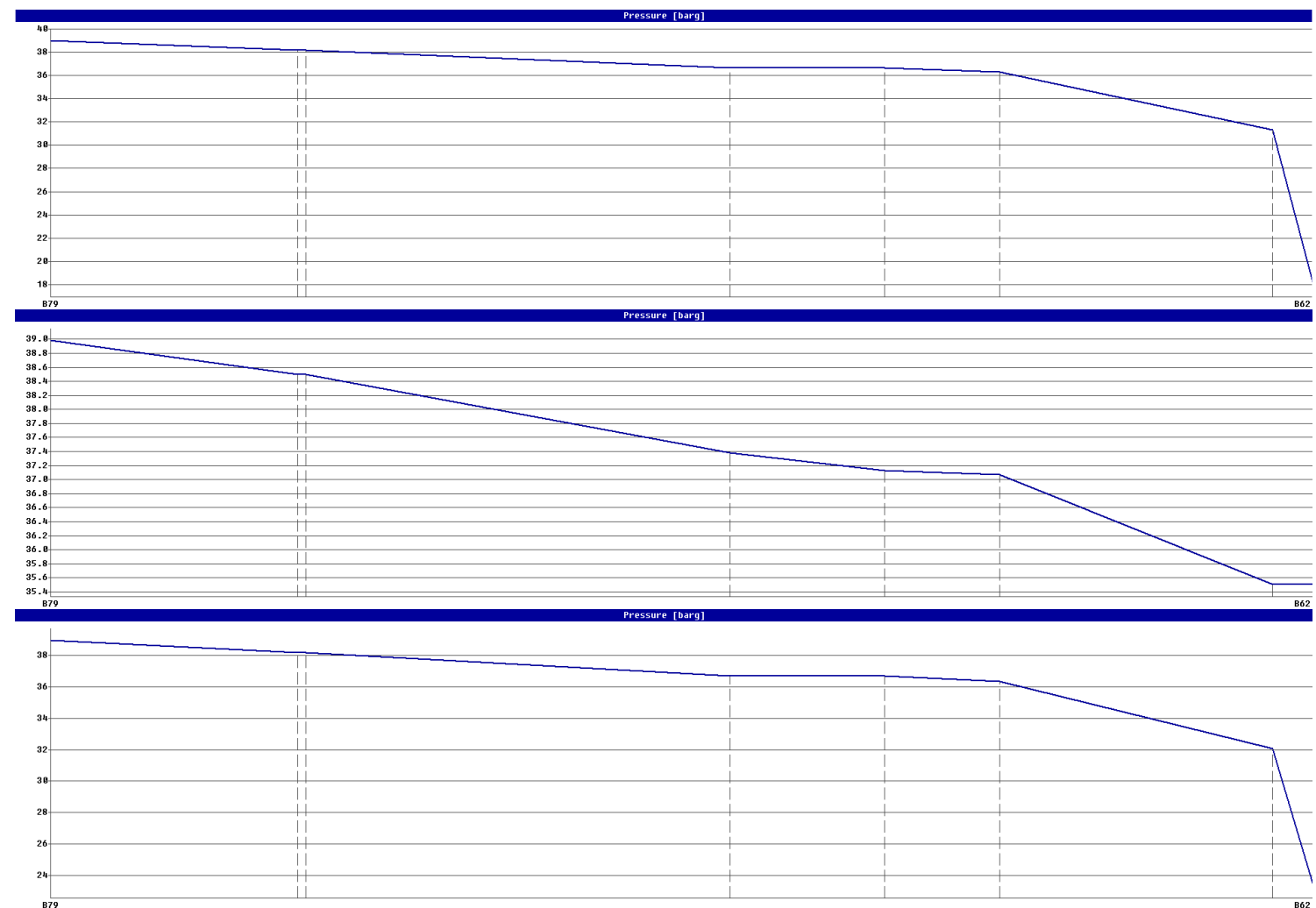

Fig. 7 Pressure variation on a route at: 0:00 hr - day 1, 19:00 hrs - day 1 and 08:00 hrs - day 3 
When choosing a gas pipe run consisting of several pipelines and analyzing it at various moments, there can be noticed a significant change of the flow's parameters. Figures $\mathbf{7}$ and $\mathbf{8}$ present the pressure variations in two pipe runs at three different moments. The pressure rise that is graphically marked in Fig. 8 is due to the compression station existing on that route.

In Fig. 9 it is presented a sequence of 3 moments at which the flow variations in a pipeline run were analyzed.

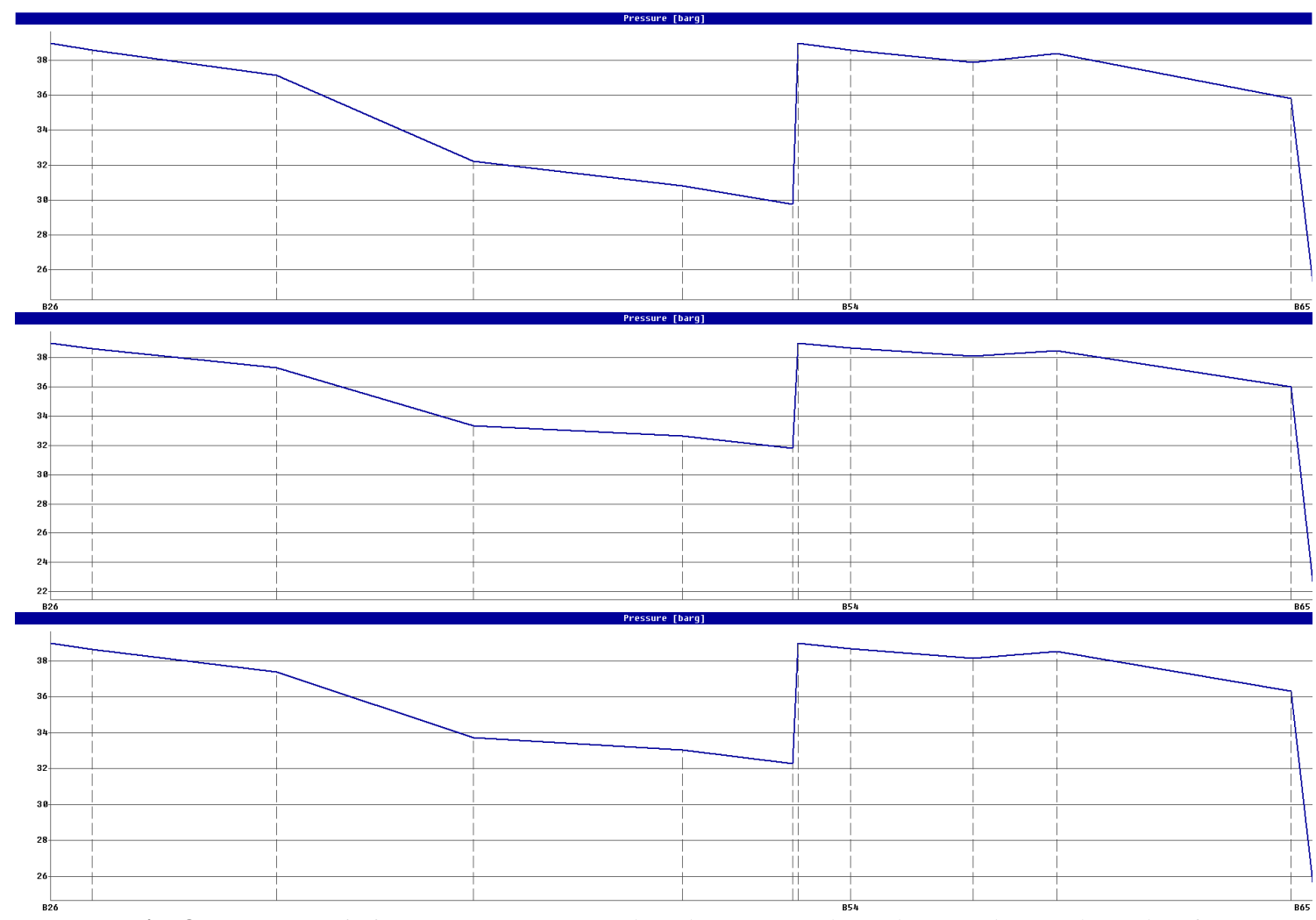

Fig. 8 Pressure variation on a route at: 0:00 hr - day 1, 23:00 hrs - day 4 and 10:00 hrs - day 6

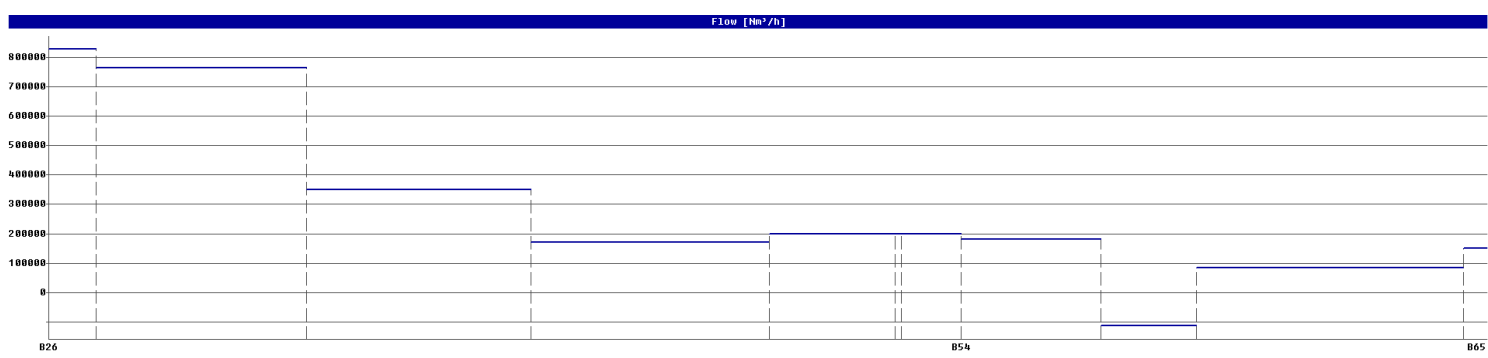




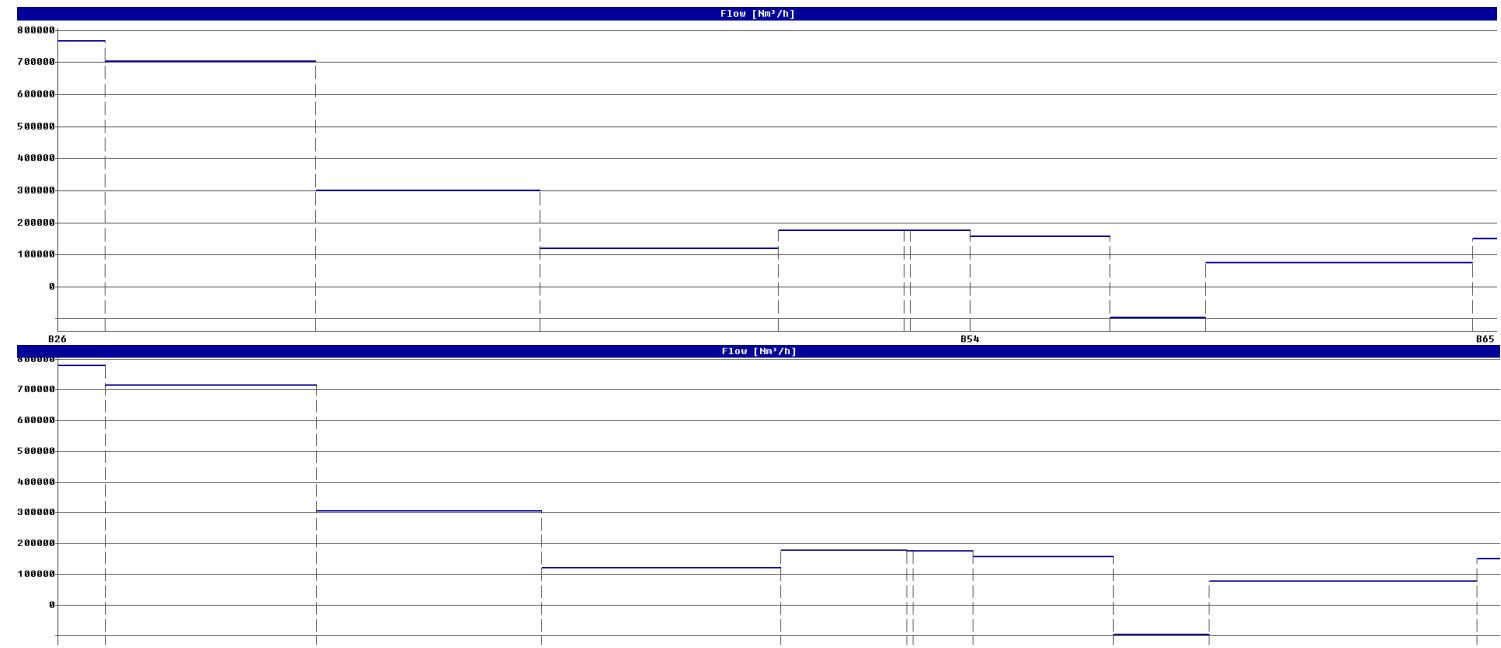

Fig. 9 Flow variation on a route at: 0:00 hr - day 1, 23:00 hrs - day 4 and 10:00 hrs - day 6

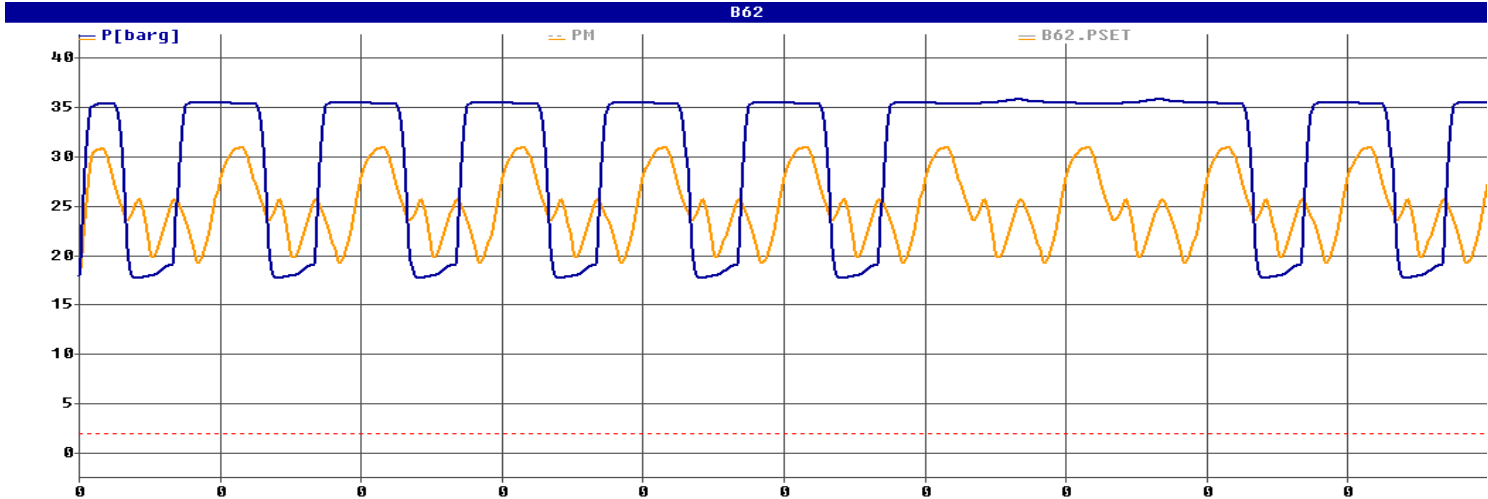

Fig. 10 Pressure variation for an industrial consumer (blue-winter, orange-summer)

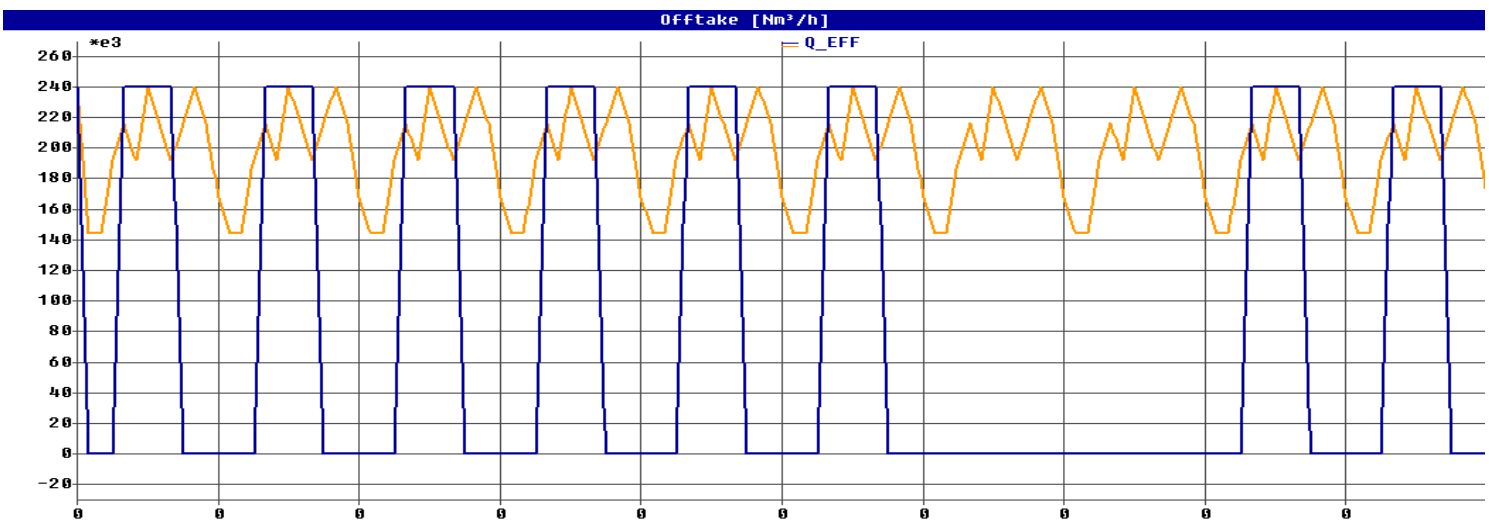

Fig. 11 Flow variation for an industrial consumer (blue-winter, orange-summer) 
The nonstationary character of gas transportation is also proven by different consumption levels that are seasonally-determined, especially in case of domestic consumers. A comparison between summer and winter consumptions is presented in Fig. 10 and 11, where pressure and flow variations for an industrial consumer are graphically represented.

During the exploitation of the gas transport networks, there occur various problems, one of the most important being that of changing parameters of a network's gas supply. In order to demonstrate the major impact of such a problem, there was constructed a simulation scenario in which the supply pressure for one of the import sources falls, throughout a period of $22 \mathrm{hrs}$ from 40 bars to 32 bars (Fig. 12). Figure 13 presents the variation of flow in the source due to the variant pressure. There may be noticed a dramatic decrease of the input flow for several minutes as a result of the falling pressure triggered by the feeding problem and a sudden rise of the input flow, once the pressure homes to the initial value.

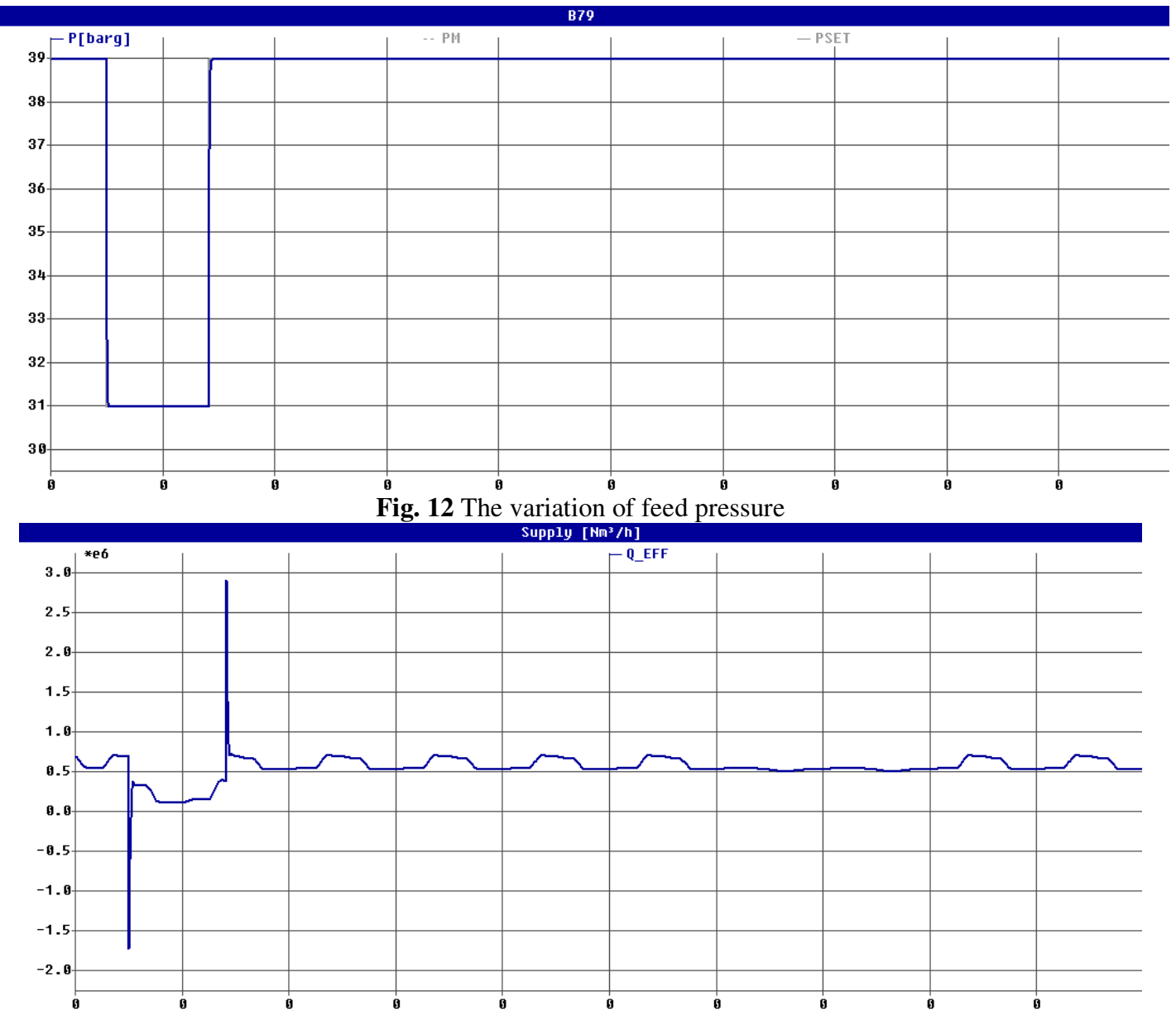

Fig. 13 The variation of feed flow 
The effect of this problem is also evident in the pressure for some consumers, but also in nearby sources. In Fig. 14, 15 and 16 it can be noticed that the influence of the feeding problem is higher in case of near-by consumers and gets lower and lower as the consumer is far away. When changing the source pressure due to the problems occurred, neighbouring sources are also affected (Fig. 17), in that they will have to compensate the lacking volume of gas by pumping in the pipelines an increased flow during that period (Fig. 18).

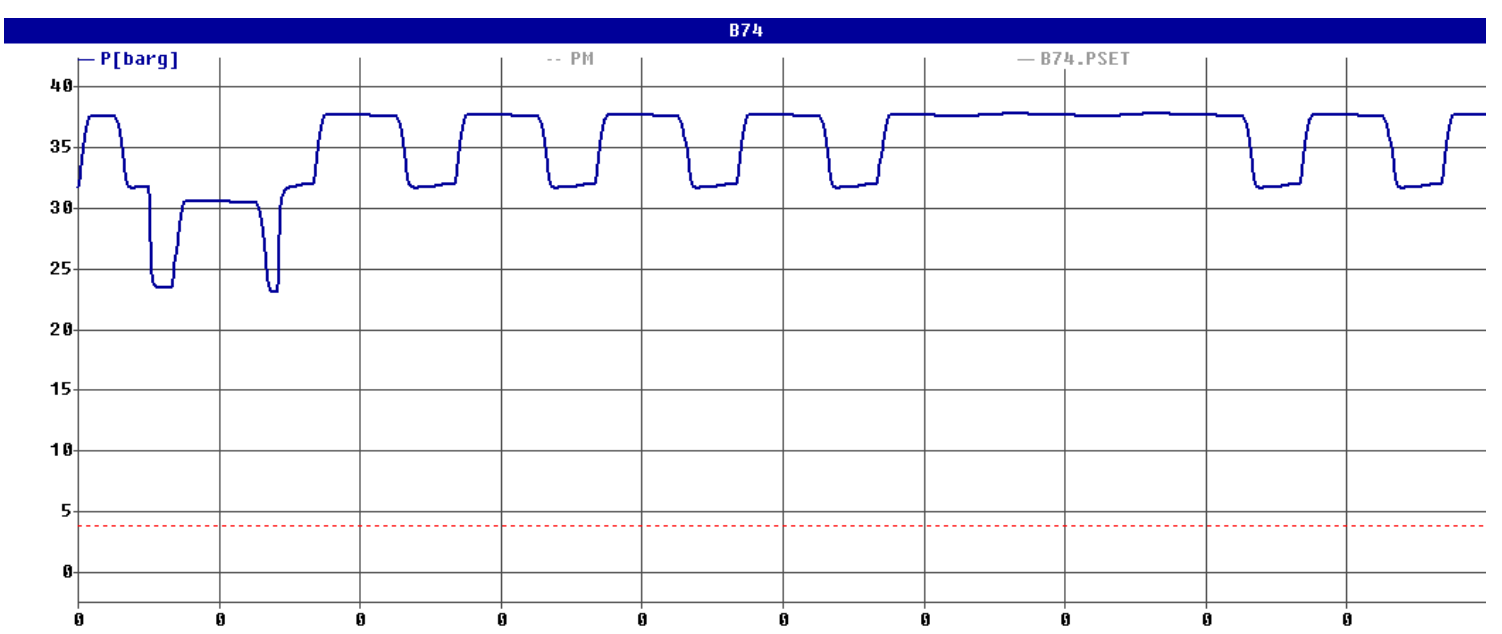

Fig. 14 Pressure variation for a consumer near the problematic source

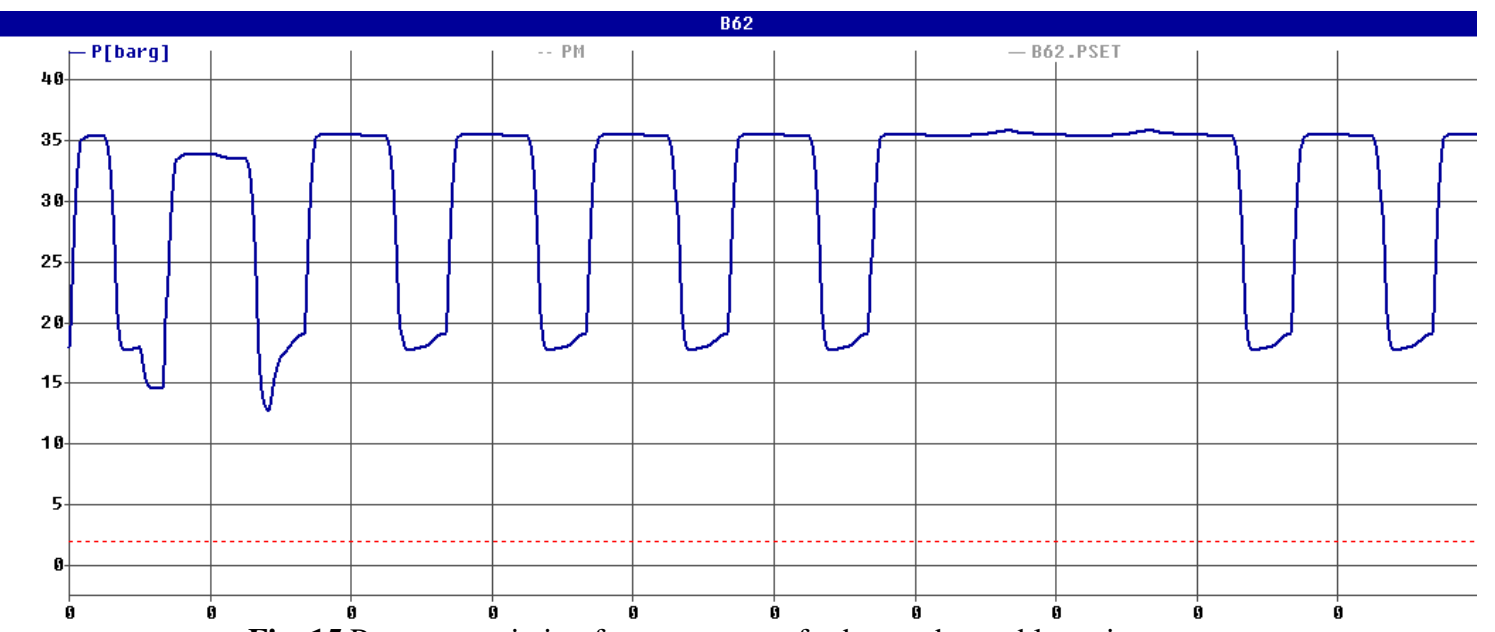

Fig. 15 Pressure variation for a consumer farther to the problematic source 


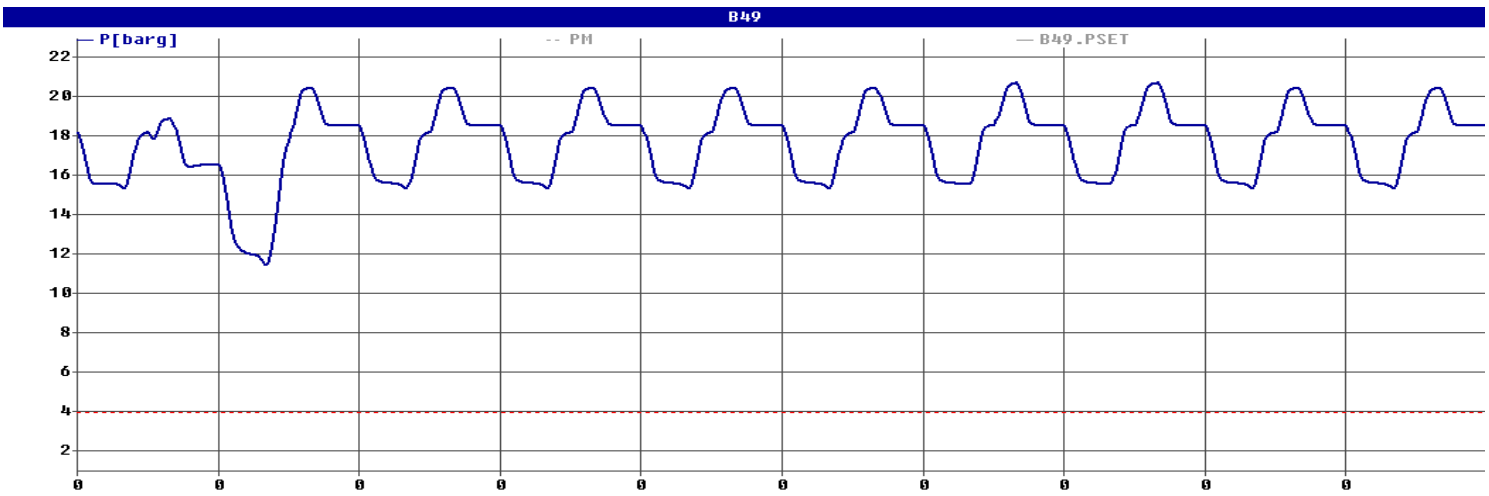

Fig. 16 Pressure variation for a consumer that is far from the problematic source

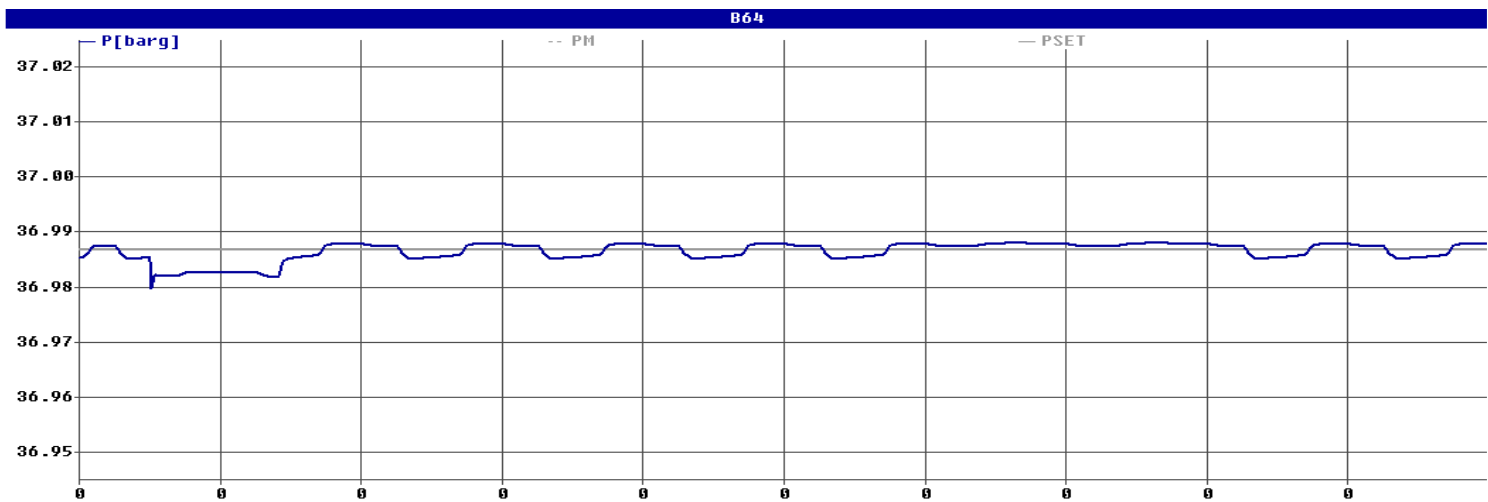

Fig. 17 Pressure variation at a gas source affected by falling import pressure

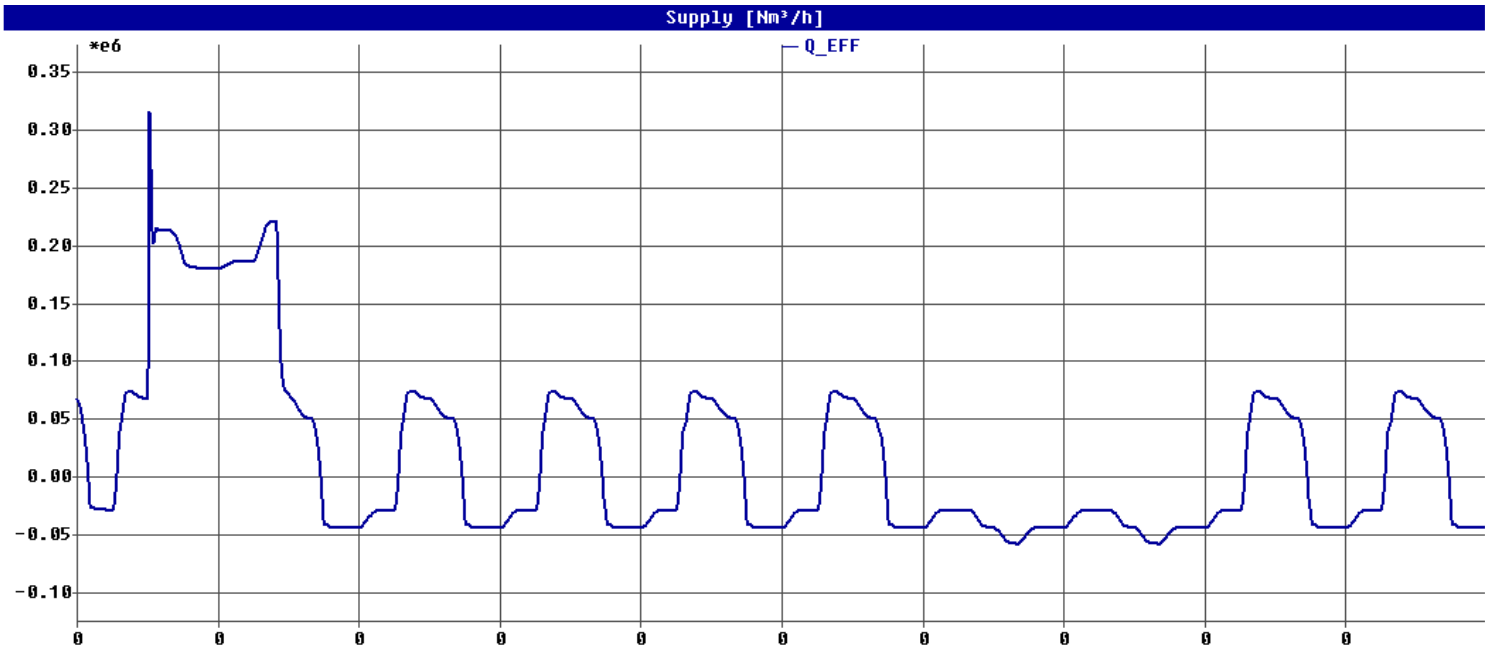

Fig. 18 Flow variation at a gas source affected by falling import pressure 
Furthermore, we shall extend the analysis over the pipe run, as presented in Fig. 19, in order to better notice the changes of parameters over time and position. In Fig. 20 and $\mathbf{2 1}$ one can observe the variations of pressure and flow throughout the pipe run, at five different moments: 0:00 hr - day 1,
13:00 hrs - day 1, 18:00 hrs - day 1, 11:00 hrs - day 2, 19:00hrs - day 2.

As a result of irregular consumptions in certain segments of the pipe run, pressure may vary dramatically, up to 8 bars.

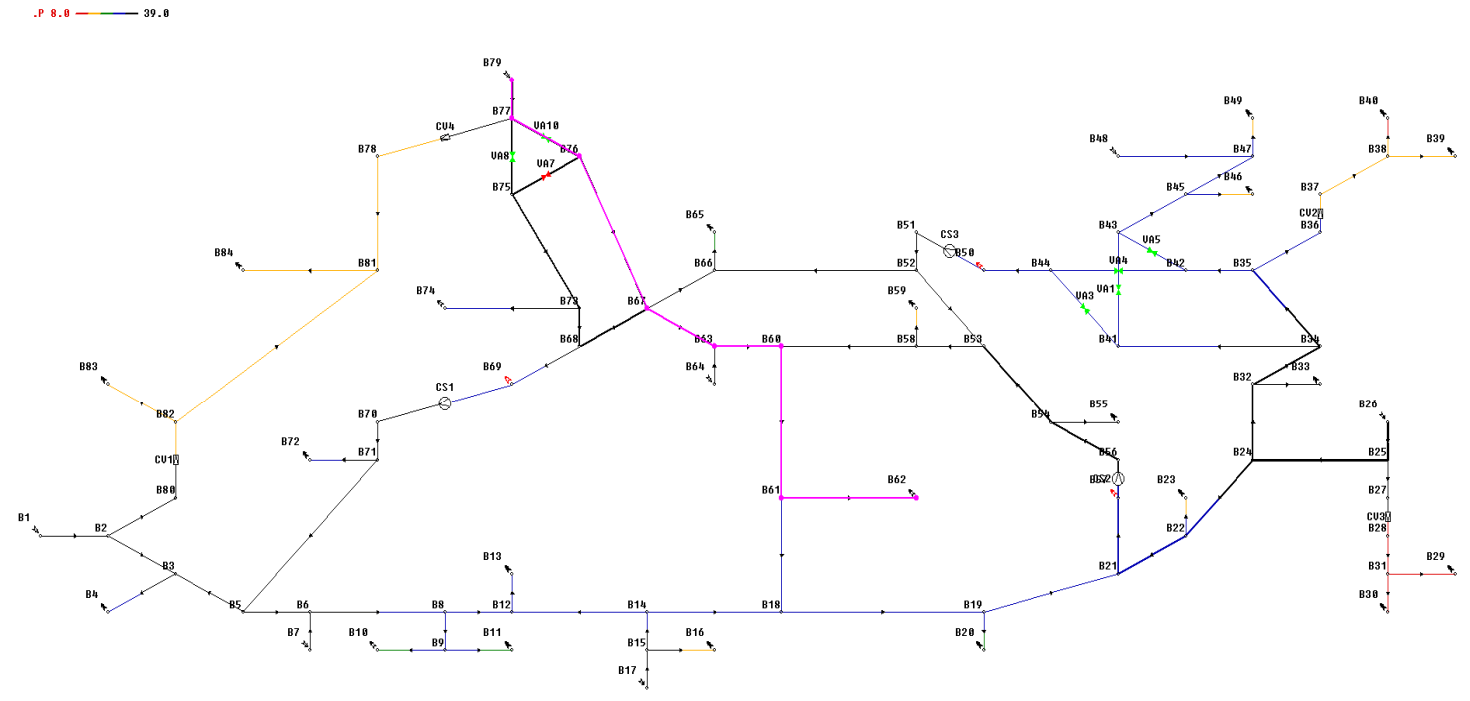

Fig. 19 Pipeline run

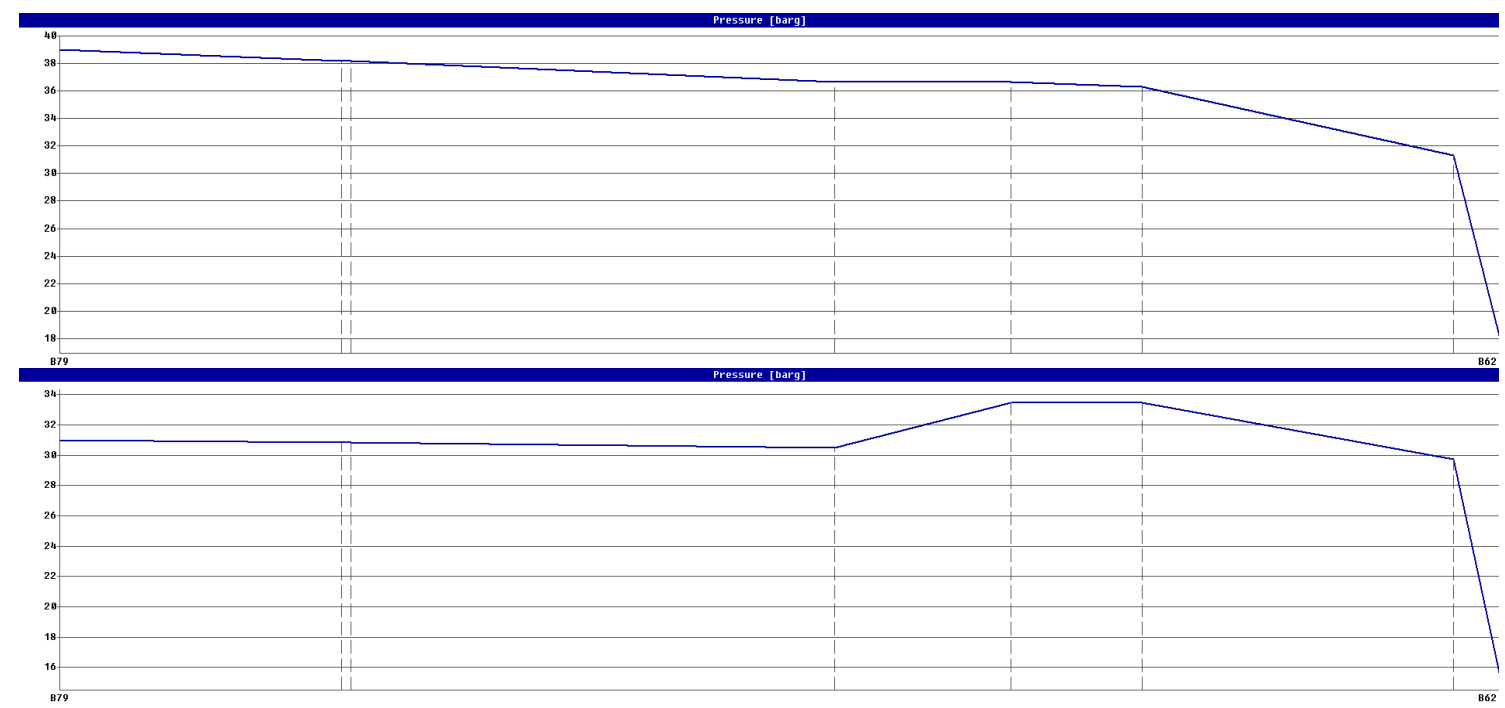



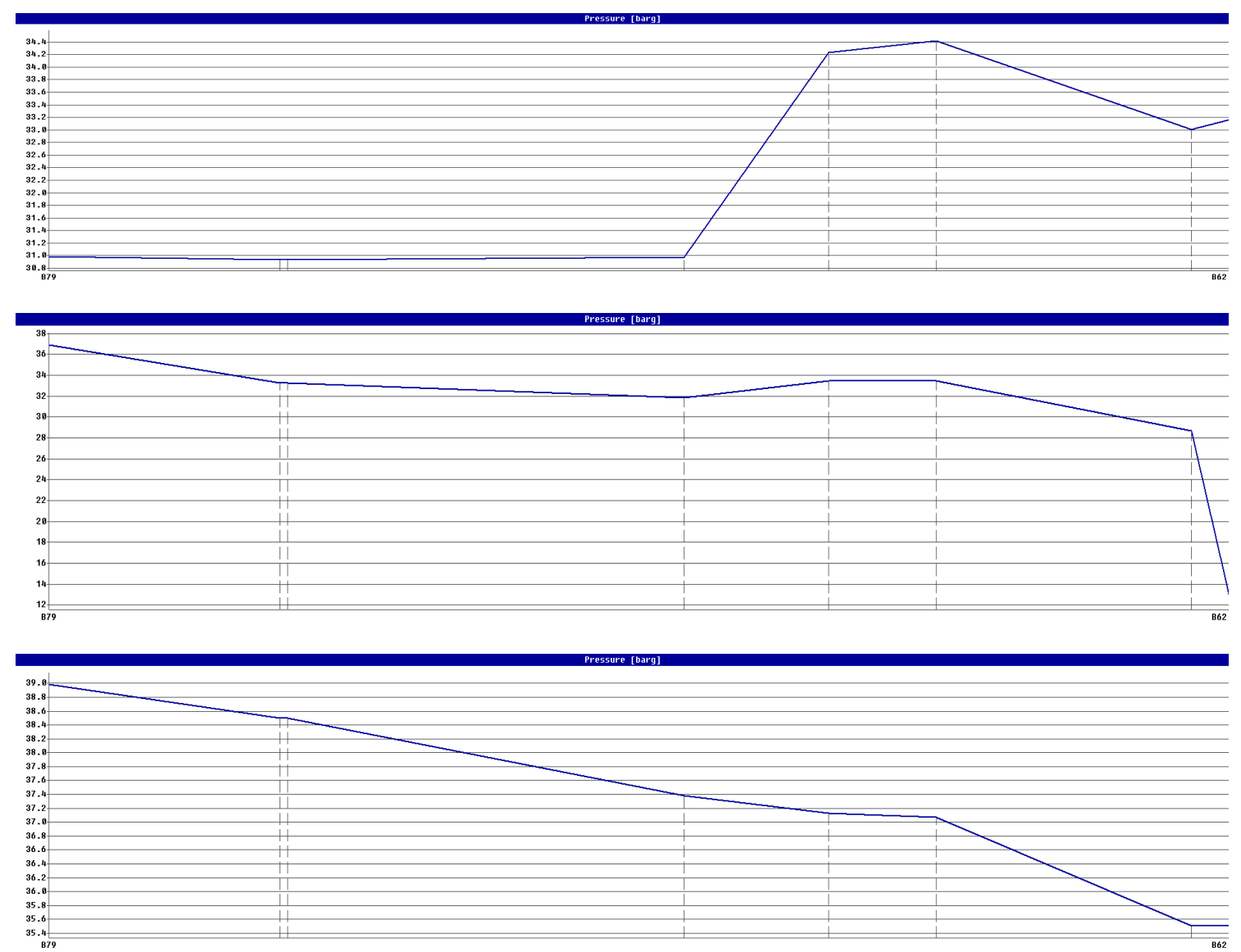

Fig. 20 Pressure variation in the pipeline run at different hours : 0:00 hr - day 1, 13:00 hrs - day 1, 18:00 hrs day $1,11: 00 \mathrm{hrs}$ - day 2, 19:00hrs - day 2

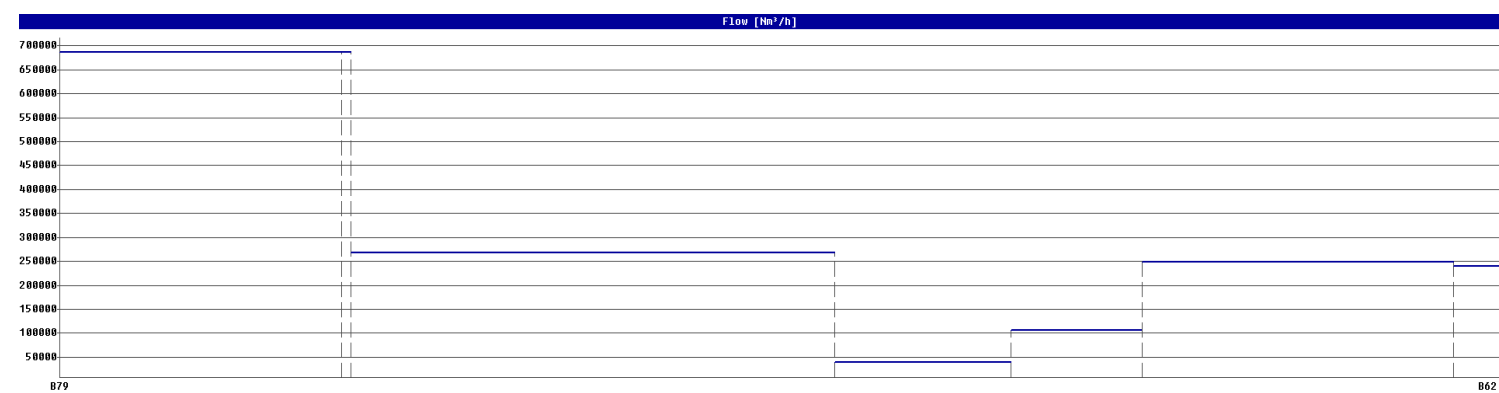




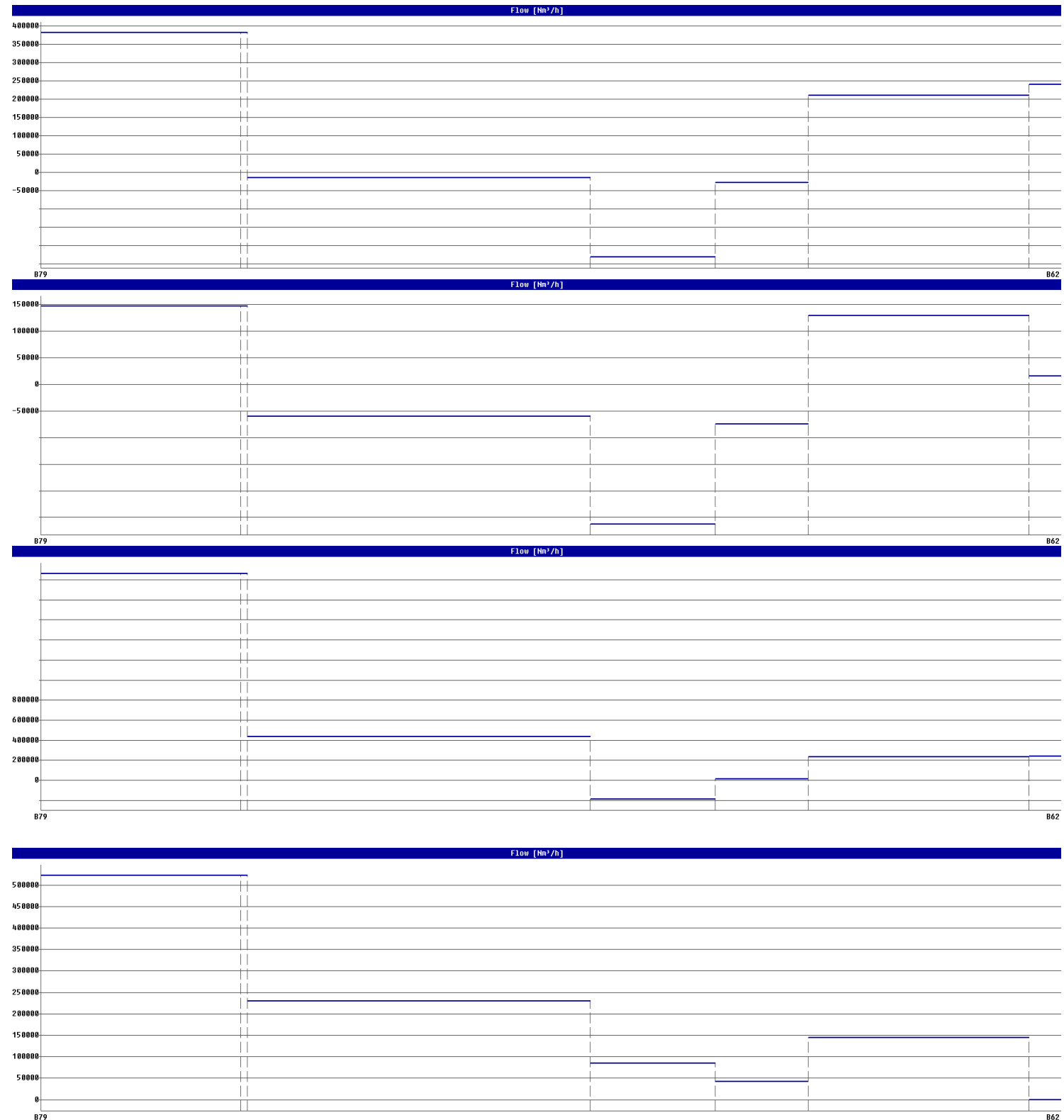

Fig. 21 Flow variation in the pipeline run at different hours : 0:00 hr - day 1, 13:00 hrs - day 1, 18:00 hrs - day

1, 11:00 hrs - day 2, 19:00hrs - day 2

There were also registered major changes in gas circulation because of the flow speeds in the pipeline run at 11:57, 12:00, 12.15 and 12:30. As one may notice, in the first pipelines there is a negative speed after 12.00, which signifies that the gas flow direction goes into reverse. 

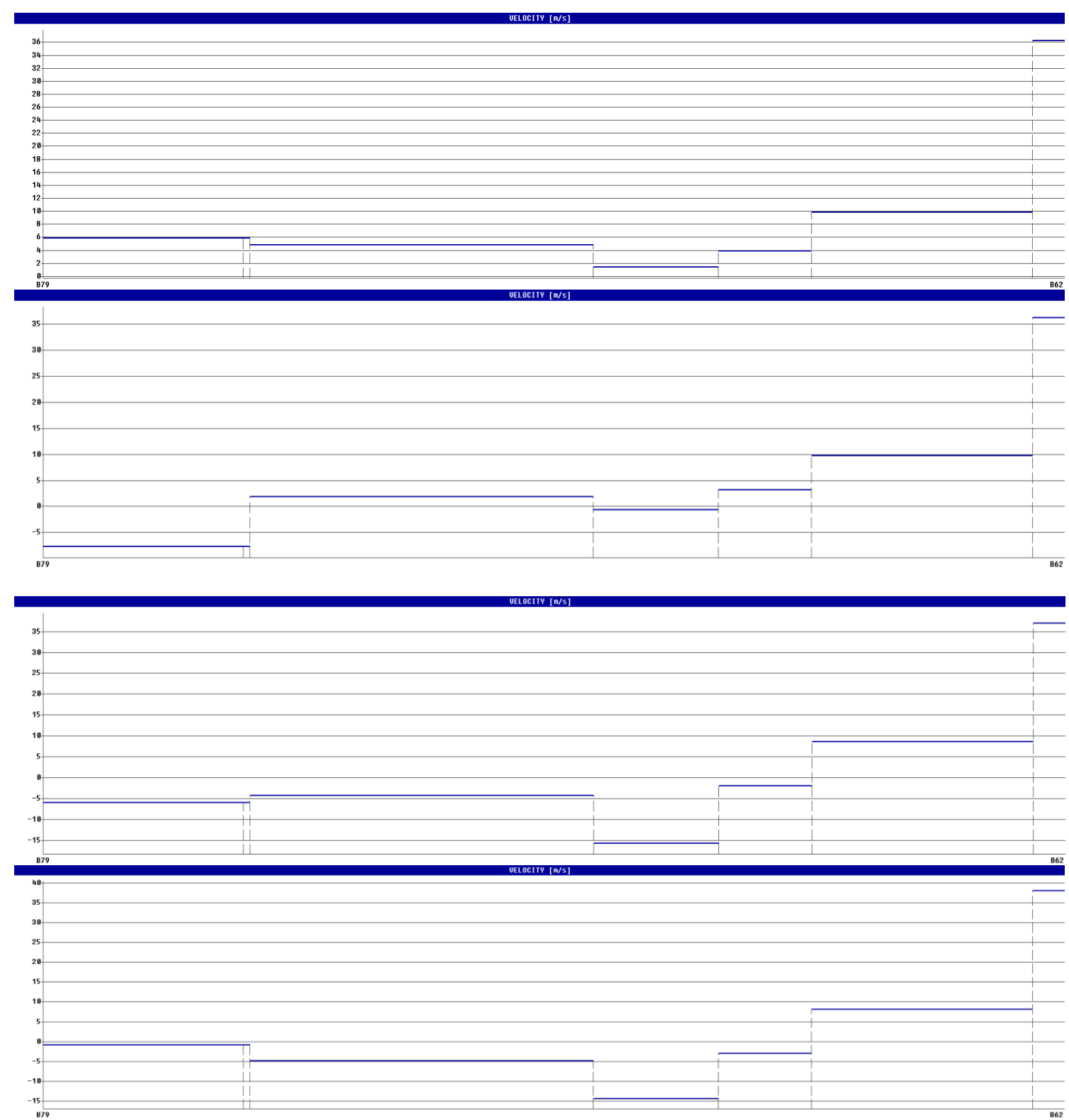

Fig. 22 Speed variation in the pipelines from the pipe run, before and after the problem occurred : 11:57, 12:00, 12.15 and $12: 30$

The example of changing flow parameters, by means of a comparative analysis of the linepack variation when there are feeding problems (blue) and in case of normal run (orange) is relevant when analyzing the dynamics of the gas flow in the pipelines. 


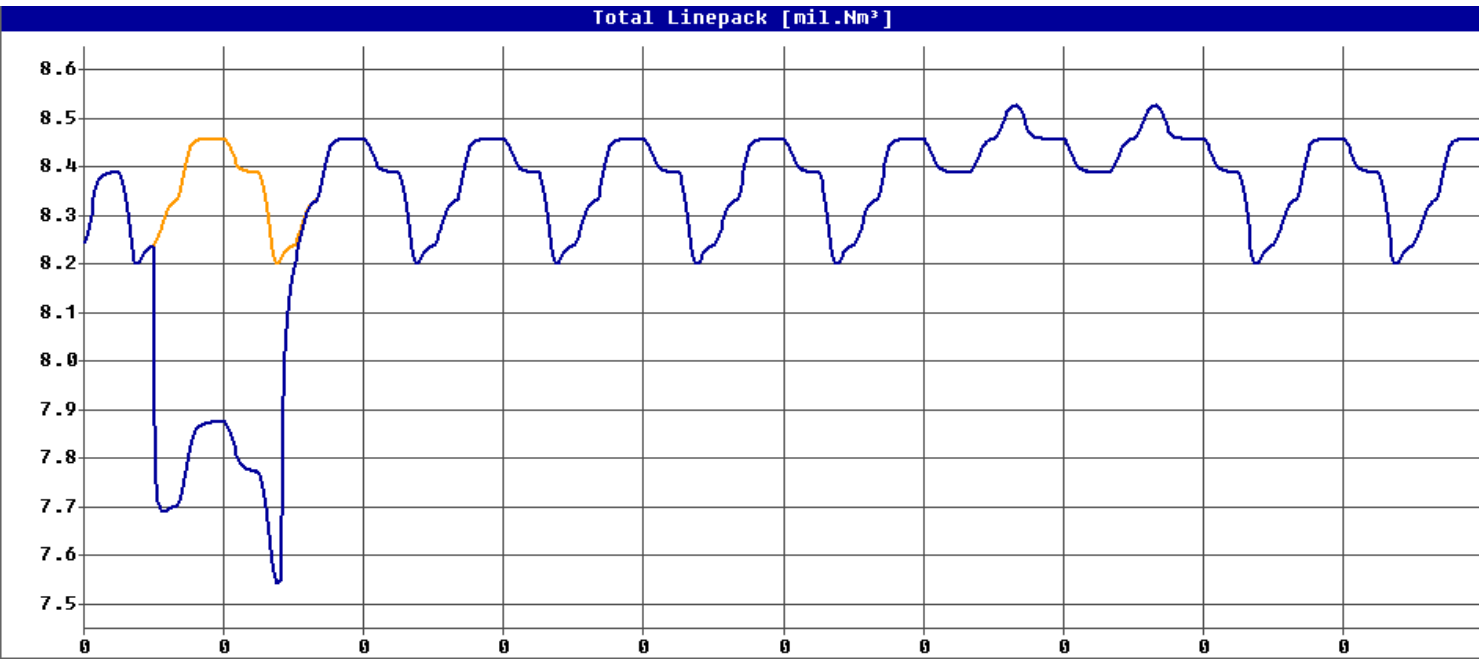

Fig. 23 Comparison between the linepack variations throughout the 10 days of surveillance in case of feeding problem (blue) and in normal functioning conditions (orange)

\section{Conclusions}

The analysis of the results presented in this paper reveals the fact that the process of gas transportation has a pronounced nonstationary character that is influenced by a series of factors. The most important factors that affect flow dynamics are: hourly, daily and annual consumption profiles of the domestic consumers, the variation of the gas supplies delivered to the industrial consumers as a consequence of major economic changes, technical problems that occur in the network or in the operation of the gas transport system. The problems caused by perturbing factors could be more easily solved if the operation of the network followed certain rules. Another possible solution would be the increase of the pressure in the Romanian pipelines to values similar to the ones from the Western gas transportation systems $(60-$ 80 bars), so that, in case a problem occurs, the linepack will allow the normal functioning of the system for the transit period.

Increasing the number of gas sources and realizing interconnections with the neighbouring systems have beneficial effects on the stabilization of the gas transportation functioning.

\section{References}

*Email: cristian.eparu@gmail.com

[1]. I. Creţu and Al. Stan, Fluid Transport through Pipelines. Applications and Problems (in Romanian) Technical Publishing House, Bucureşti, 1984

[2]. C. Eparu, S. Neacşu, M. Albulescu and R. Rădulescu, Considerations on the Simulation of Gas Flow Dynamics in Transport Systems (in Romanian) Termotehnica Revue, Supplement no. 1/ 2011

[3]. C. Trifan, M. Albulescu and S. Neacşu, Fluid Mechanics and Technical Thermodynamics (in Romanian) Petroleum-Gas University Publishing House, 2005, Ploiești.

[4]. G.-Y. Zhu, M.A. Henson, L. Megan, Dynamic modeling and linear model predictive control of gas pipeline networks, Journal of Process Control, Volume 11, Issue 2, 2001, 129-148

[5]. A.S. Manne, K. Roland, G. Stephan, Security of supply in the Western European market for natural gas, Energy Policy, Volume 14, Issue 1, 1986, 52-64

[6]. *** http://www.simone.eu/simone-company-about.asp

[7]. *** GTE comments on - Calculation of Available Capacities: Understanding and Issues - An ERGEG Public Consultation Paper, 09 August 2007

Submitted: May $20^{\text {th }} 2013$ Accepted in revised form: August $20^{\text {th }} 2013$ 